\title{
Statistical Analysis in Bioequivalence studies
}

\author{
Souza RM* \\ Academic Department of Mathematics, Federal Technological University of Paraná, Brazil
}

Submission: September 19, 2017; Published: November 10, 2017

* Corresponding author: Roberto Molina de Souza, Academic Department of Mathematics, Federal Technological University of Paraná, Campus Cornélio Procópio, PR, Brazil, email: rmolinasouza@utfpr.edu.br

Keywords: Generic drugs; Bioequivalence studies; Statistical analysis; Bivariate models

Abbreviations: ANOVA: Analysis of Variance; $\mathrm{C}_{\max }$ : Maximum Concentration; $\mathrm{AUC}_{0-\mathrm{t}}$ : Area under the Curve

\section{Introduction}

In order to evaluate the interchangeability of two or more formulations, bioequivalence studies are recommended. The goal of these studies is to present evidences of similar bioavailability [1]. In many countries, these studies are necessary for the commercialization of generic drugs. The pharmacokinetic parameters are calculated in order to quantify bioavailabilities, which leads to a comparison of relative bioavailability [2]. Generally, the pharmacokinetic parameters considered in a bioequivalence study are the Maximum Concentration $\left(\mathrm{C}_{\max }\right)$ and the Area under the plasma concentration curve $\left(\mathrm{AUC}_{0-\mathrm{t}}\right)$ at a previously defined time. These parameters are obtained directly from the plasma concentration curve of each individual, for each study formulation.

\section{Statistical analysis}

From a literature review presented by Barret et al. [3], the interest in comparing bioavailabilities began around 1960. In this way, Grizzle [4] published a paper using Analysis of Variance (ANOVA) model to compare bioavailabilities using pharmacokinetic parameters. In practice, bioequivalence studies should be applied to the inspection of generic drugs in order to demonstrate the same effect of formulations with proven safety and efficacy. Therefore, the interest of the statistical test of hypotheses was the non-rejection of equality of pharmacokinetic parameters according to the formulations under study. Thus, Westlake [5] proposed a hypothesis test for the bioequivalence decision in which the confidence intervals for the mean difference of each pharmacokinetic parameter, according to the formulations under study, should be fully contained within previously established limits of bioequivalence.

Although Anderson \& Hauck [6] have proposed a method for bioequivalence assessment called individual bioequivalence, regulatory agencies around the world have adopted the average bioequivalence method proposed by
Westlake [5] and have provided guidelines for standardizing bioequivalence studies. Basically, the model adopted for the evaluation of mean bioequivalence from a cross-over study consists of a random and fixed effects model or mixed model $[6,7]$. In this model, the effects of formulation, period and sequence are the fixed effects. Random effects are calculated for each individual receiving all formulations under study at different periods and random sequences. The difference between means is obtained from the formulation effect. The sequence and period effects are expected to be non-significant. Finally, it is assumed that the residuals of this model have a normal distribution, independently and identically distributed with constant variance (standard model).

From the standard model, many authors began to propose more sophisticated models as the same purpose, to compare average bioequivalence. Ghosh \& Rosner [8] proposed a semiparametric model in which they relax the assumption of normality of residues. In another paper, Ghosh \& Gönen [9] and Souza et al. [10] present models for bivariate bioequivalence analysis, since the bioequivalence decision considers the analysis of two possibly correlated pharmacokinetic parameters. Recently, Souza et al. [11] presented a bioequivalence model considering asymmetric distributions in the univariate and bivariate context of the bioequivalence analysis. They presented a study of the power of bioequivalence hypothesis test, in which the use of extended generalized gamma distribution may be a good alternative to logarithmic transformation or non-parametric analyzes when assumptions of normality are not checked for the standard model.

\section{Final considerations}

The standardization of bioequivalence studies by regulatory agencies is very important for safety in the bioequivalence approval process. On the other hand, the assumptions of 
a standard model may not be verified. In this sense, the improvement of the bioequivalence models is indispensable, since, the models have to be adjust to the data and not the opposite.

\section{References}

1. Hyslop T, Hsuan F, Holder DJ (2000) A small sample confidence interval approach to assess individual bioequivalence. Stat Med 19(20): 28852897.

2. Metzler CM (1974) Bioavailability - a problem in equivalence. Biometrics 30(2): 309-317.

3. Barrett JS, Batra V, Chow A, Cook J, Gould AL, et al. (2000) PhRMA perspective on population and individual bioequivalence. J Clin Pharmacol 40(6): 561-570.

4. Grizzle JE (1965) The two-period change-over design an its use in clinical trials. Biometrics 21(2): 467-480.
5. Westlake WJ (1972) Use of confidence intervals in analysis of comparative bioavailability trials. J Pharm Sci 61(8): 1340-1341.

6. Anderson S, Hauck WW (1990) Consideration of individual bioequivalence. J Pharmacokinet Biopharm 18(3): 259-273.

7. McLean RA, Sanders WL, Stroup WW (1991) A unified approach to mixed linear models. American Statistical Associaton 45(1): 54-64.

8. Ghosh P, Rosner GL (2007) A semi-parametric Bayesian approach to average bioequivalence. Statistics in Medicine 26(6): 1224-1236.

9. Ghosh P, Gönen M (2008) Bayesian modeling of multivariate average bioequivalence. Statistics in Medicine 27(13): 2402-2419.

10. Molina SR, Achcar JA, Martinez EZ (2009) Use of Bayesian methods for multivariate bioequivalence measures. J Biopharm Stat 19(1): 42-66.

11. Souza RM, Achcar JA, Martinez EZ, Mazucheli J (2016) The use of asymmetric distributions in average bioequivalence. Statistics in Medicine 35(15): 2525-2542.
Your next submission with Juniper Publishers will reach you the below assets

- Quality Editorial service

- Swift Peer Review

- Reprints availability

- E-prints Service

- Manuscript Podcast for convenient understanding

- Global attainment for your research

- Manuscript accessibility in different formats

( Pdf, E-pub, Full Text, Audio)

- Unceasing customer service

Track the below URL for one-step submission https://juniperpublishers.com/online-submission.php 